\title{
REVIEW ARTICLE \\ Ex vivo pulsed dendritic cell vaccination against cancer
}

\author{
Yang-zhuo Gu' ${ }^{1}$ Xing Zhao ${ }^{1,2}$ and Xiang-rong Song ${ }^{1}$
}

As the most powerful antigen-presenting cell type, dendritic cells (DCs) can induce potent antigen-specific immune responses in vivo, hence becoming optimal cell population for vaccination purposes. DCs can be derived ex vivo in quantity and manipulated extensively to be endowed with adequate immune-stimulating capacity. After pulsing with cancer antigens in various ways, the matured DCs are administrated back into the patient. DCs home to lymphoid organs to present antigens to and activate specific lymphocytes that react to a given cancer. Ex vivo pulsed DC vaccines have been vigorously investigated for decades, registering encouraging results in relevant immunotherapeutic clinical trials, while facing some solid challenges. With more details in DC biology understood, new theory proposed, and novel technology introduced (featuring recently emerged mRNA vaccine technology), it is becoming increasingly likely that ex vivo pulsed DC vaccine will fulfill its potential in cancer immunotherapy.

Keywords: cancer immunotherapy; dendritic cells; cancer antigens; DC vaccination; mRNA-pulsed DC vaccines; T-cell activation; tumor microenvironment

Acta Pharmacologica Sinica (2020) 41:959-969; https://doi.org/10.1038/s41401-020-0415-5

\section{INTRODUCTION}

Vaccination is a type of immunotherapy that is effective in the treatment of cancer. It provides the immune system with potential antigens for recognition and usually activates antigen-specific lymphocytes via presentation of antigens by dendritic cells (DCs), which are the most adept cells regarding antigen uptake and processing. Activated lymphocytes, especially $\mathrm{T}$ cells, assume effector functions such as cytotoxicity and cytokine production to controlling cancer progression.

Before the prevalence of dendritic cell vaccines, studies on cell-based vaccines focused on inactivated tumor cells that were engineered for enhanced immunogenicity. The so-called whole-cell cancer vaccines generally require antigen uptake by endogenous DCs, which is a process that is relatively limited in efficiency. This strategy is reasonably advantageous because the antigens are delivered directly to DCs for maximum efficacy, and this can be done either by ex vivo pulsing or in vivo targeting of DCs.

Ex vivo pulsing of DCs is a process in which DCs that are derived from autologous origins are loaded with antigens and matured under favorable ex vivo conditions. The resulting DCs are then administered back to the patient to initiate protective immune responses. Compared with in vivo targeting, ex vivo pulsing of DCs has a lower risk, higher efficiency, and fewer technical difficulties.

U.S. FDA approval of Sipuleucel-T, a vaccine against late-stage castration-refractory prostate cancer and notably the first therapeutic DC vaccine against cancer, ushered cancer immunotherapy into a new era. Although numerous DC-based cancer vaccines have entered clinical trials in recent years and have registered encouraging results, many issues have yet to be addressed. In this review, we discuss recent progress in and the future of vaccination with ex vivo pulsed DCs against cancer, with an emphasis on emerging mRNA-pulsed DC vaccines.

\section{BIOLOGY OF DCS}

In 1973, Steinman and Cohn discovered a cell population with branching processes and named these cell DCs after the Greek word for tree (dendreon) [1]. Decades of in-depth study of this heterogeneous population finally verified that they are the most potent professional antigen-presenting cells, which bridge the gap between innate and adaptive immunity and play a key role in eliciting adaptive immune responses. Steinman was awarded the Nobel Prize in 2011 for the remarkable discovery of DCs.

DCs exist in two sequential stages, immature and mature DCs (mDCs) after. Most DCs in the body are immature, and they populate peripheral nonlymphoid tissues, specialize in antigen uptake, express high levels of phagocytosis-related receptors and low levels of costimulatory molecules, such as CD80 and CD86, as well as adhesion molecules, such as ICAM, and exhibit weak antigen-presenting capacity; hence, these cells are relatively incompetent at activating $T$ cells [2].

Immature DCs (iDCs) migrate to peripheral lymphoid organs after ingestion of antigen and stimulation by inflammatory factors. Maturation proceeds during migration, resulting in DCs that express high levels of major histocompatibility complex (MHC) molecules and costimulatory molecules, such as CD40, CD70, CD80, and CD86, and secrete interleukin 12 (IL-12), IL-6, TNF-a, and IP-10. Furthermore, $\mathrm{mDCs}$ express increased levels of $\mathrm{C}-\mathrm{C}$ chemokine receptor type 7, a chemokine receptor that is responsible for lymph node homing. These molecules are vital for effective T-cell activation [3]. mDCs present antigens to and

\footnotetext{
${ }^{1}$ State Key Laboratory of Biotherapy and Cancer Center, West China Hospital, Sichuan University, and Collaborative Innovation Center for Biotherapy, Chengdu 610041, China and

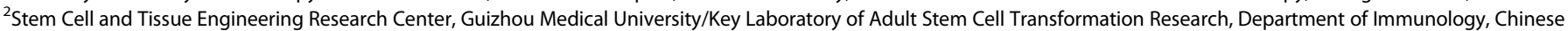
Academy of Medical Sciences, Guiyang 550004, China Correspondence: Xiang-rong Song (songxr@scu.edu.cn)
}

Received: 15 December 2019 Accepted: 30 March 2020

Published online: 4 May 2020 


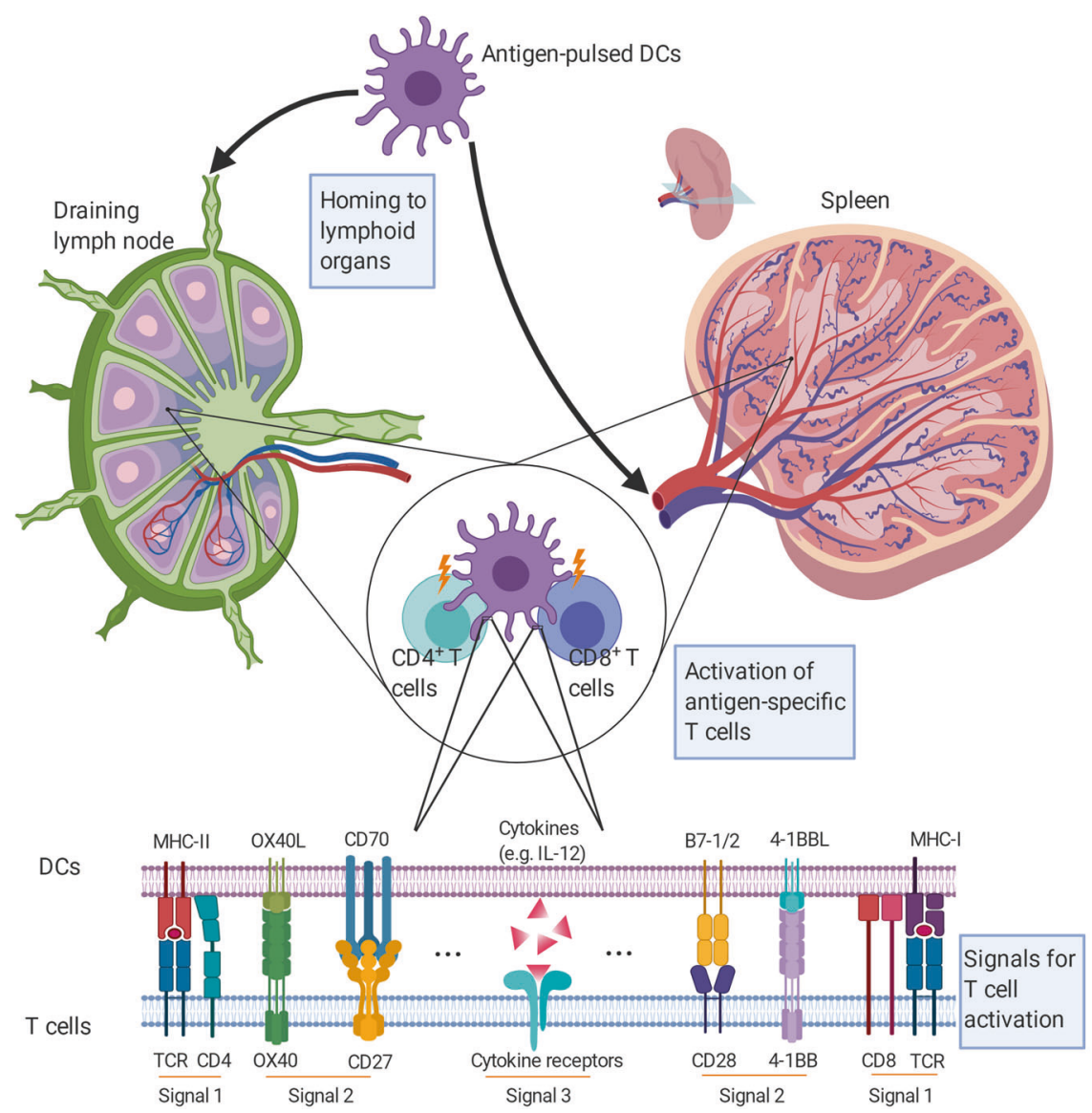

Fig. 1 Activation of antigen-specific T cells by DCs. Antigen-pulsed DCs home from peripheral tissues to lymphoid organs, where they present processed antigens to encountered T cells for specific recognition. Full activation of T cells is collectively governed by three different signals, provided by TCR recognition of peptide-MHC complex, co-stimulation, and tonic cytokines signaling.

activate T cells in the lymph nodes. Full activation of naïve T cells depends on the orchestration of three distinct signals. DCs present peptide-MHC complexes to T cells for recognition by specific T-cell receptors, and the $\mathrm{CD} 3$ complex transduces an antigen recognition signal (Signal 1 ) into T cells. Signal 2 is determined by a balance between costimulatory and coinhibitory molecules on DCs (CD80, CD86, PD-L1/2, CD40, CD70, OX40L, 4-1BBL, etc.) and T cells (CD28, CTLA-4, PD-1, CD40L, CD27, OX40, 4-1BB, etc.). Signal 3 is from the cytokine environment, which regulates the proliferation, differentiation, and immune memory of T cells (Fig. 1). For example, IL-12 secreted by DCs promotes Th1 (T helper 1) immune responses, while IL-23, IL- 6 , and IL- $1 \beta$ stimulate Th17 immune responses [4-6]. Activated T cells, such as cancer-specific cytotoxic $T$ lymphocytes (CTLs), leave peripheral lymphoid organs for cancer foci, where they exert their anticancer function. Moreover, DCs interact with natural killer (NK) cells and further boost anticancer effects. Recently, it was found that mDCs enhance NK cell proliferation, activation, and cytotoxicity through the interaction of DC-expressed CX3CL1 and NK cell-expressed CX3CR1, as well as through the secretion of cytokines, such as IL-12, IL-15, and IL-18 [7].

\section{VACCINATION WITH EX VIVO PULSED DENDRITIC CELLS-THE BASICS AND THE REGULAR STORY}

Preparation of DCs

Despite their general presence in most tissues, the absolute numbers of DCs are low. For example, mDCs account for only $~ 1 \%$ of total peripheral blood mononuclear cells (PBMCs). As ex vivo derivation of DCs improves, multiple precursor cells can be used to prepare DCs, such as nonproliferative $C D 14^{+}$monocytes from peripheral blood and proliferative $\mathrm{CD} 34^{+}$precursor cells from bone marrow and the umbilical blood $[8,9]$. In addition, various cell types can be redirected to a dendritic cell fate either by direct transdifferentiation or indirect dedifferentiation followed by redifferentiation (Fig. 2).

$\mathrm{CD}_{14}{ }^{+}$monocytes constitute $\sim 10 \%$ of PBMCs, and DCs derived from peripheral blood monocytes (MoDCs) have been extensively studied and applied. In 1994, Sallusto and Romani established a method for the induction of DCs from monocytes by granulocyte-macrophage colony-stimulating factor (GM-CSF) and IL-4. GM-CSF sustains differentiation toward and subsequent development of DCs, while IL-4 suppresses the proliferation of macrophages and granulocytes and prevents the differentiation of monocytes toward macrophages $[10,11]$. Two years later, Romani and Zhou made an improved protocol public. They obtained iDCs after induction for 6-7 days with GM-CSF and IL-4 and then developed $\mathrm{mDCs}$ after stimulation for 3 days with activating factors such as TNF-a. This method also registered the first successful effort to replace bovine serum with human plasma in culture, which lays the foundation for the clinical application of ex vivo-derived DCs $[12,13]$.

To date, more ex vivo derivation protocols of MoDCs have been explored, such as replacing IL-4 with IL-15 or interferon a (IFN-a) in the presence of GM-CSF to bolster the activation potency of DCs [14-16]. Apart from the classical 1-week protocol, researchers invented fast protocols with which DCs could be harvested after 2-3 days of culture [17].

The maturation of DCs was commonly performed by adding the gold standard cocktail (TNF-a, IL-1 $\beta$, IL-6, and prostaglandin E2) to 


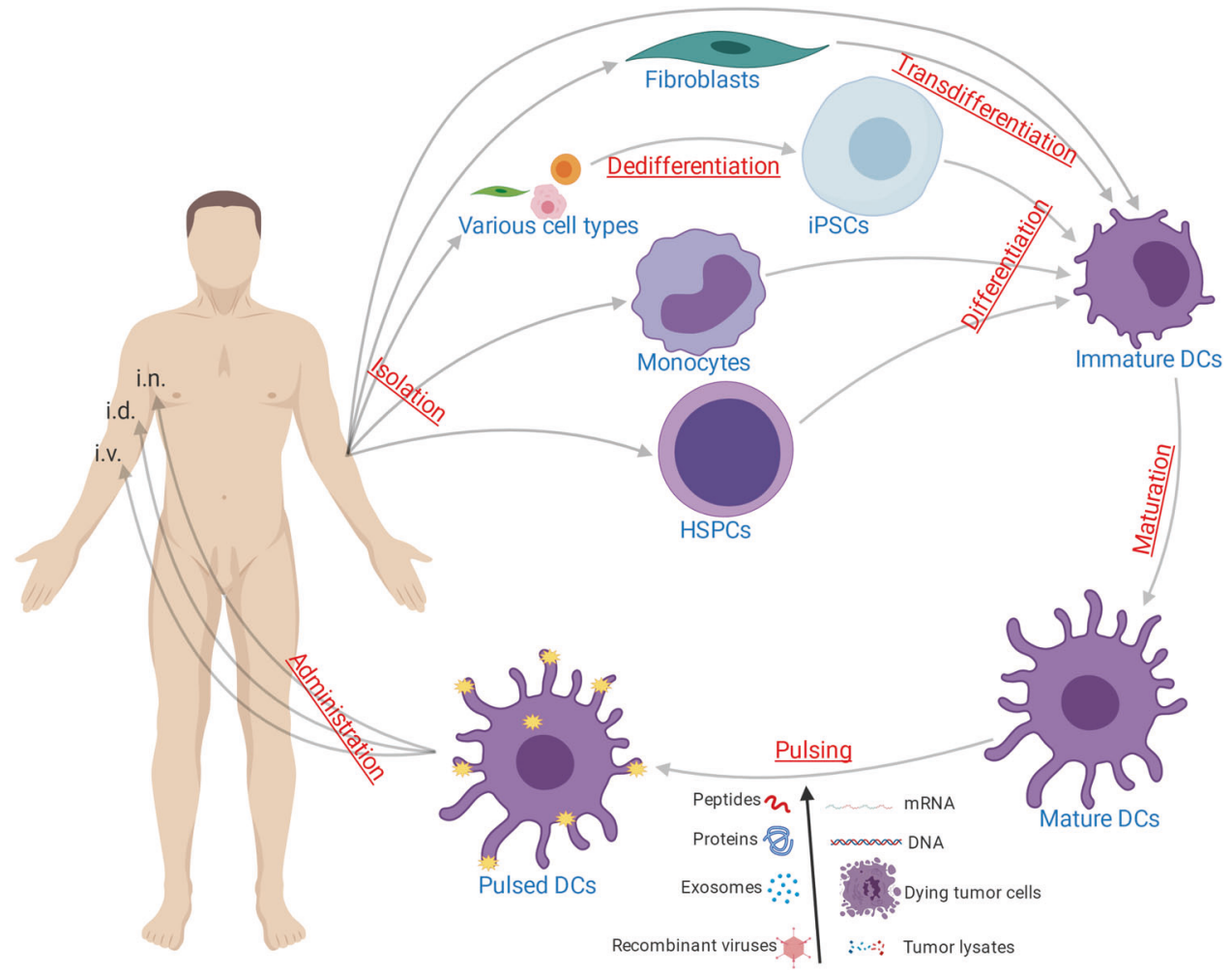

Fig. 2 Schema of vaccination with ex vivo pulsed DCs against cancer. DCs are typically generated from autologous CD14 ${ }^{+}$monocytes, HSPCs, and differentiated into immature DCs in the presence of various stimuli. Also, DCs can be derived from fibroblasts by transdifferentiation, and from iPSCs. In addition, existing DCs are isolated from patients. After maturation and pulsing with antigen of diverse forms, mature DCs are administered back into the patients via various routes. i.n. intranodally. i.d. intradermally. i.v. intravenously.

cultures [18]. Later, different teams developed somewhat similar modifications to the formulation (IFN- $\gamma$ and LPS/MPLA) $[19,20]$.

MoDCs cannot be propagated ex vivo; as a result, their application is somewhat limited. $\mathrm{CD}_{3} 4^{+}$hematopoietic stem/ progenitor cells (HSPCs) can be used to prepare DCs in large amounts ex vivo. These DCs (34DCs) are superior to MoDCs in that they elicit more potent T-cell immune responses against cancer by upregulating the expression of tumor necrosis factor-related apoptosis-inducing ligand and enhancing cytotoxicity [21, 22].

Derivation of robust 34DCs was typically achieved in a cytokine milieu that differed from that for MoDC derivation. The combination of fms-related tyrosine kinase 3 ligand (Flt $3 \mathrm{~L})$, thrombopoietin (TPO), and stem cell factor (SCF) was one of the first documented formulations for such a purpose. Alternatively, culturing in the presence of Flt $3 \mathrm{~L}, \mathrm{SCF}, \mathrm{IL}-3$, and IL- 6 for 3 weeks before switching to culture in the presence of Flt3L, TPO, and SCF for 1 week worked similarly well [23]. Recently, it was reported that the inclusion of Notch ligand Delta-like 1 (DLL1) in the original formulation of GM-CSF, Flt3L, and SCF significantly improved the induction of bona fide type 1 conventional DCs (CDC1s), which specialize in priming $\mathrm{CD}^{+} \mathrm{CTLs}$, from CD34 ${ }^{+}$HSPCs [24].

Efforts to dissect the hematopoietic progenitor subsets that give rise to $34 D C s$, especially $C D C 1 s$, revealed that, aside from the widely recognized common myeloid progenitor lineage, a large proportion of multipotent lymphoid progenitors share the same potential [25].

As the understanding of the signals that govern cell differentiation continued to deepen, fresh strategies for deriving DCs were developed. Forced coexpression of PU.1, IRF8, and BATF3 transdifferentiated fibroblasts into $\mathrm{CDC} 1 \mathrm{~s}$ that were competent for cell therapy [26]. Alternatively, various cell types can be efficiently dedifferentiated into induced pluripotent stem cells (iPSCs) before being redifferentiated into DCs [27]. This process is a once-and-for-all solution that generates DCs in unprecedented quantities, although it is currently not time- or budget-friendly. Recently, it was demonstrated that iPSCs derived from primary DCs were a superior source of DCs for immunotherapy, as the epigenetic imprints retained after dedifferentiation helped to ensure high immunogenicity of the generated DCs [28].

Pulsing of DCs with cancer antigens

The pulsing of DCs with cancer antigens is the key step in preparing DC vaccines. DCs are usually pulsed with whole-cell antigens from ultrasonicated or repeatedly frozen and thawed cancer samples, synthetic cancer antigenic peptides, DNA or RNA from cancer cells, and exosomes derived from cancer cells [29-32] (Fig. 2). Tumor antigenic peptides are synthesized according to verified or predicted epitopes in cancer antigens and are used in many clinical trials to pulse DCs. However, there are considerable weaknesses in this approach. For example, epitopes are restricted by the HLA (human leukocyte antigen) type of the patients, most cancer antigenic epitopes are not yet elucidated, and peptides may only serve to elicit either $\mathrm{CD}^{+}{ }^{+}$or $\mathrm{CD} 8^{+} \mathrm{T}$-cell responses [33]. Furthermore, the half-life of the HLA-antigenic peptide complex is relatively short, thus limiting the duration of presentation [34]. Exosomes from cancer cells carry abundant cancer antigens, and exosome-pulsed DCs are more efficacious than tumor lysates, presumably because DNA in exosomes activates DCs through the CGAS/STING pathway and promotes DC maturation and presentation, thereby eliciting more potent immune responses against cancer $[35,36]$. However, it remains difficult to obtain large quantities of highly purified exosomes.

Apart from the aforementioned method of loading, pulsing DCs ex vivo with mRNAs encoding cancer antigens has emerged conspicuously in recent years, which will be discussed later in this review. 
Conventional clinical applications of DC vaccines

DC vaccines have a similar clinical objective response rate (ORR) to other conventional therapies against cancer. For example, the ORR of melanoma patients receiving DC immunotherapy is $8.5 \%$, which is similar to the rate of those receiving the first-line drug dacarbazine. Likewise, the ORRs of patients with prostate cancer, malignant glioma, and renal cell carcinoma receiving DC immunotherapy are $7.1 \%, 15.6 \%$, and $11.5 \%$, respectively, which are similar to the rates of those receiving conventional chemotherapy [37].

In a phase III clinical trial of a DC vaccine for the treatment of glioblastoma, all enrolled patients were randomly grouped after surgery and chemotherapy. The treatment group received the autologous DC vaccine (DCVax-L) and temozolomide, while the control group received temozolomide and a placebo. DCVax-L was prepared from autologous DCs that were activated by lysates of surgically excised tumor tissues. The results indicated that the treatment group achieved a median overall survival (mOS) of 23.1 months compared with a mOS of only 15-17 months for those who received surgery alone. In addition, 67 patients (30\%) survived longer than 30 months, $44(24.2 \%)$ survived longer than 36 months, the regimen was well tolerated, with only $2.1 \%(7 / 331)$ of the patients exhibiting Grade III-IV adverse events [38].

Vaccination of melanoma patients with DCs pulsed with mutated peptides of neoantigens enhanced T-cell immune responses directed against not only dominant neoantigens but also subdominant ones, thus expanding the breadth of reaction and strengthening the potency of the vaccine [39]. Preconditioning with recall antigens such as Tetanus toxoid unilaterally before vaccination with DCs pulsed with cancer antigens stimulated bilateral DC migration to lymph nodes that drained the vaccination sites, thereby enhancing the efficacy of DC vaccination. The effects depended on both the $\mathrm{CD} 4^{+}$T-cell recall response to antigens used for preconditioning and the host CCL3 chemokine [40].

In a trial of 34DC immunotherapy of melanoma, 18 enlisted HLA $A^{*} 0201^{+}$patients were administered 34DCs pulsed with antigenic peptides of melanoma-associated tyrosinase, gp100, MART-1, and MAGE-3 antigens, along with those of control antigens. Sixteen patients responded to at least one melanoma antigen, and ten responded to more than two melanoma antigens. Of the ten potential good responders, only one had progressive disease, and seven experienced regression of metastases [41].

The results of these and many other studies [42-44] suggest that vaccination with ex vivo pulsed DCs is efficacious against cancer with minor, if any, side effects. The anticancer efficacy of DC vaccines can be reinforced once procedures, such as loading DCs with tumor antigens, culture of DCs ex vivo and the route of administration, are further optimized (Figs. 2, 3).
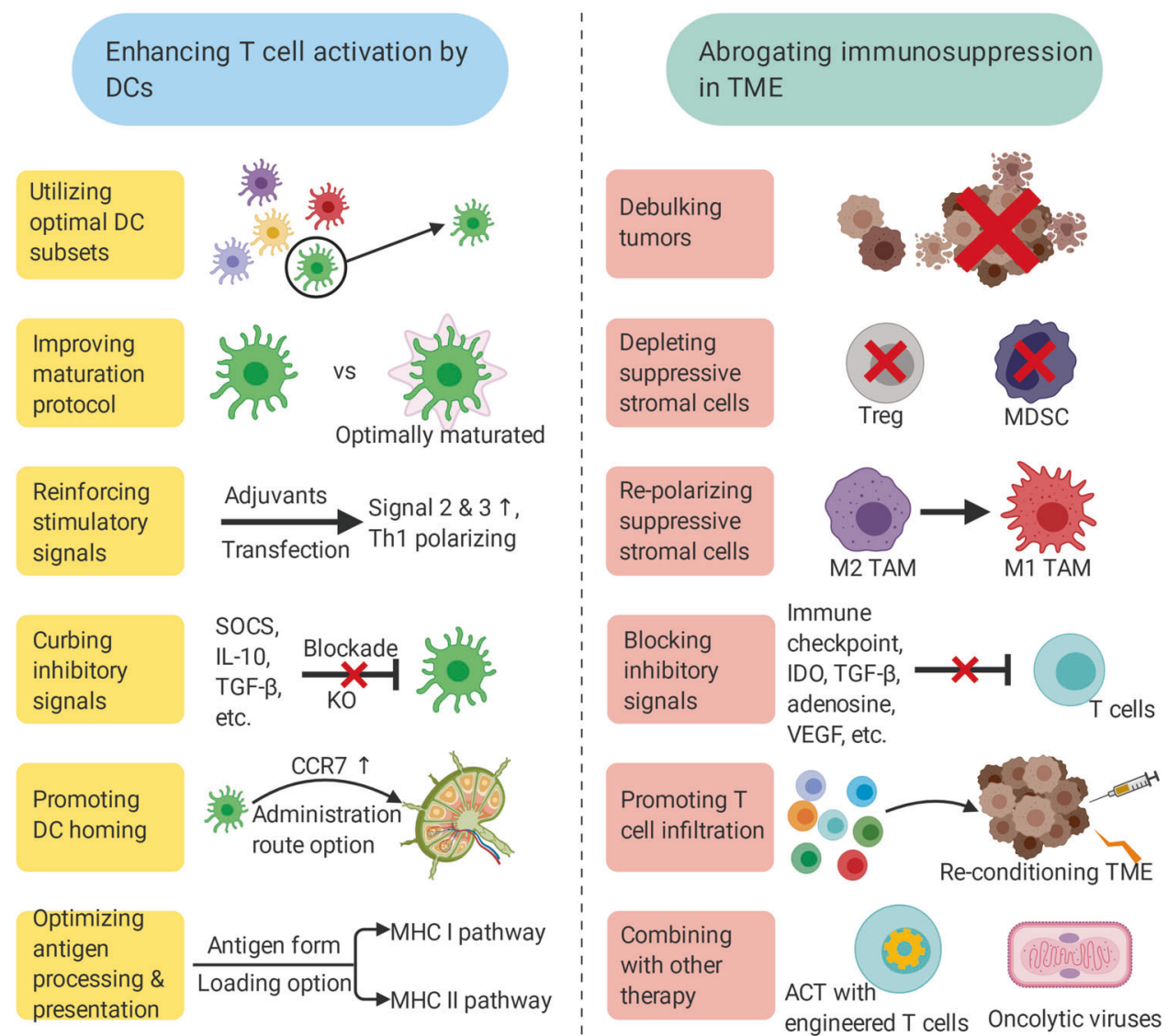

Fig. 3 Possible determinants of a successful DC vaccination. Induction of potent cancer antigen-specific T cells by DCs and improving the performance of tumor-infiltrating T cells are two processes that are relatively separate spatially, yet interconnected. The former can be done by utilizing optimal DC subsets, improving maturation protocol, reinforcing stimulatory signals, curbing inhibitory signals, promoting DC homing, optimizing antigen processing and presentation, etc. The latter can be attained by debulking tumors, depleting suppressive stromal cells, repolarizing suppressive stromal cells, blocking inhibitory signals, promoting T-cell infiltration, combining with other therapy, etc. Note that each measure listed is not an isolated case, and may have profound influence on each other. $\uparrow$ upregulation. Th1 Type 1 helper T cells. SOCS suppressor of cytokine signaling. KO knockout. CCR7 C-C chemokine receptor type 7. MHC major histocompatibility complex. TME tumor microenvironment. Treg regulatory T cell. MDSC myeloid-derived suppressor cell. TAM tumor-associated macrophage. ACT adoptive cell transfer. 


\section{NEW EMERGENCE OF MRNA-PULSED DC VACCINES AGAINST} CANCER

mRNA for DC pulsing

mRNA is widely recognized as an ideal tool for the preparation of DC vaccines $[45,46]$ because of its unique traits. mRNA does not integrate into the genome, avoiding any potential insertional mutagenesis. mRNA can be readily produced in large amounts in vitro in a process that is both technologically mature and costefficient. mRNA can be engineered to increase immunogenicity and reduce inhibition of its translation. mRNA is degraded by physiological mechanisms, facilitating the control of effects in a timed fashion. mRNA is not subject to splicing as pre-mRNA is, eliminating any uncertainty in protein products due to alternative splicing. After the introduction of mRNA into DCs, specific T-cell responses targeting multiple epitopes can be elicited, mitigating the risk of immune evasion through antigen variation [47].

Since mRNA-pulsed DC vaccines have stepped into the research spotlight, a paradigm shift away from DC vaccines pulsed in a conventional fashion is taking place.

mRNA used for DC pulsing includes cancer-derived and in vitro transcribed mRNA. Cancer-derived mRNA conveys the full repertoire of epitopes of a given cancer, expanding the range of antigens to which the immune system responds, thus preventing evasion resulting from antigen downregulation or loss. However, preparing tumor-derived mRNA requires either a large number of tumor cells or amplification of isolated mRNA. In either case, the majority of all mRNAs encode unaltered selfantigens, a small portion of which (tissue-specific, mutated, and aberrantly expressed ones) are deemed as potentially appropriate targets for vaccination. The mRNAs that encode altered self-antigens and foreign antigens may become underrepresented or even lost during processing. Moreover, the process is both time-consuming and laborious and is thus unfavorable for clinical application.

mRNA encoding cancer antigens can be transcribed in vitro from templates of open reading frame (ORF)-containing plasmids or other DNA fragments. Rational design of cap, $5^{\prime}$ and $3^{\prime}$ untranslated regions (UTRs) and poly (A) tail structure of mRNAs, and even the sorting signals attached to the antigen, as well as the nucleotide sequence of the ORF itself and the introduction of modified nucleotides, strengthens mRNA stability, enhances translation, improves antigen processing and presentation, avoids vigorous recognition by innate immune sensors, and culminates in augmented antigen-specific immune responses [48-51]. It has become increasingly clear that apart from $\mathrm{CD}^{+}{ }^{+}$cells, $\mathrm{CD} 4^{+}$ $\mathrm{T}$ cells, especially $\mathrm{Th} 1$ cells, are important participants in anticancer immunity [52]. mRNA-encoded proteins are synthesized in the cytosol of DCs and are readily processed to antigenic peptides that then associate with MHC class I molecules and are presented to $\mathrm{CD}^{+} \mathrm{T}$ cells. However, activation of $\mathrm{CD}^{+} \mathrm{T}$ cells depends on the MHC class II presentation pathway, which is not readily accessible to nonsecretory proteins in most cases. The usual solution to this problem is targeting these antigens to lysosomes by means of fusion to lysosomal sorting signals so that both $\mathrm{CD}^{+}$and $\mathrm{CD}^{+}$arms of T-cell responses can be generated against cancer antigens $[53,54]$.

The strategies discussed above are far from comprehensive, as the effects of DC vaccines are determined by multiple factors, such as the balance between costimulatory and coinhibitory molecules, as well as the balance between activating and suppressive cytokines. In light of this, there was development of the TriMix formulation, which is a mixture of constitutively activated Toll-like receptor (TLR) 4, CD40L, and CD70 mRNAs $[55,56]$. The results of various preclinical and clinical studies on TriMix indicated that it boosted the immunostimulatory function of DCs. More importantly, education by TriMix-DCs reprogrammed regulatory $\mathrm{T}$ cells (Tregs) to function like Th1 cells. An unprecedented ORR of $27 \%$ was recorded in Stage III/IV melanoma patients who were treated with TriMix-DCs (NCT01066390) [57].

Introduction of mRNA into DCs

The pioneering effort of pulsing DCs with mRNAs encoding cancer antigens was developed by Boczkowski et al. at Duke University in the late 1990s [58]. In that study, mRNA was engulfed by DCs by macropinocytosis, which was problematic in that exogenous mRNA triggers signal transduction by the TLR-7 pattern recognition receptor (PRR) pathway, and DCs activated by this signaling promptly curtail the ingestion of mRNA [59-61]. In addition, only a small fraction of mRNAs survived endosomal delivery, gained access to the cytosol, and were translated into proteins.

The methods of introducing mRNA into DCs have evolved significantly since then. Electroporation is probably the most widely adopted method for the introduction of mRNA into DCs. Unlike DNA, mRNA does not have to enter the nucleus to exert its function. Therefore, a relatively weak electric pulse is sufficient for the delivery of mRNA into the cytosol, greatly alleviating damage to the cells $[62,63]$. In addition, since mRNA introduced by electroporation avoids the endosomal route where the mRNAresponsive PRRs reside, unnecessary and potentially harmful recognition of mRNA by the innate immune system is avoided. Sonoporation exploits ultrasound to trigger the implosion of mRNA-loaded microbubbles on target cells, thus forcing entry of mRNA into cells [64]. Nanofection delivers mRNA into cells in the form of a nanomaterial-mRNA complex, which typically travels via the endocytic pathway and ultimately releases its cargo into the cytosol [65].

Clinical trials of mRNA-pulsed DC vaccines against cancer Numerous studies have confirmed that autologous DC vaccines prepared with mRNAs encoding cancer antigens are both safe and efficacious. The last two decades witnessed more than 40 clinical trials adopting such a strategy (Table 1).

In these trials, mRNAs produced by in vitro transcription, as well as those derived from autologous cancers or cancer stem cells, were used to load DCs with cancer antigens. Aside from the origins of the mRNAs, these trials also differed in activation tactics, varying from applying proinflammatory cytokines to co-delivering TriMix mRNAs. These DC vaccines were tested in the treatment of ovarian cancer, mammary cancer, late-stage melanoma, leukemia, malignant glioma, mesothelioma, pancreatic cancer, esophageal cancer, myeloma, lung cancer, etc. For most trials, DC vaccines were administered intradermally or intravenously, with some exceptions for intranodal and intratumoral administration.

In a trial involving 15 late-stage melanoma patients (NCT01066390) who received treatment of TriMix-DCs with mRNA encoding MAGE-A3, MAGE-C2, tyrosinase, and gp100 antigens (TriMix-DC-MEL), two achieved complete response, and another two achieved partial response. In six of twelve patients, antigenspecific skin-infiltrating lymphocytes were detected, and in four of five patients, antigen-specific $\mathrm{CD}^{+} \mathrm{T}$ cells were detected in the blood [57]. Also noteworthy is that recent trials tended to combine chemotherapy or antibody-targeted therapy with DC vaccines to strengthen efficacy (NCT00626483, NCT02649829, NCT02366728, and NCT02649582).

In a phase I trial of autologous Langerhans-type DCs pulsed with xenogeneic TRP-2 mRNA, stage IIB to IV melanoma patients who had their tumors resected were vaccinated 5 times at 2-week intervals. Six out of nine participants stayed disease-free for a median of 51.1 months. The patients developed clinical outcomerelated immune responses, including activation and increased clonality of $\mathrm{T}$ cells and secretion of proinflammatory cytokines, and showed minimal signs of toxicity [66].

In addition, enhanced antitumor activities were also observed in combinatorial treatment with mRNA-pulsed DCs and immune checkpoint inhibitors. In 2011, a phase II trial for the treatment of 


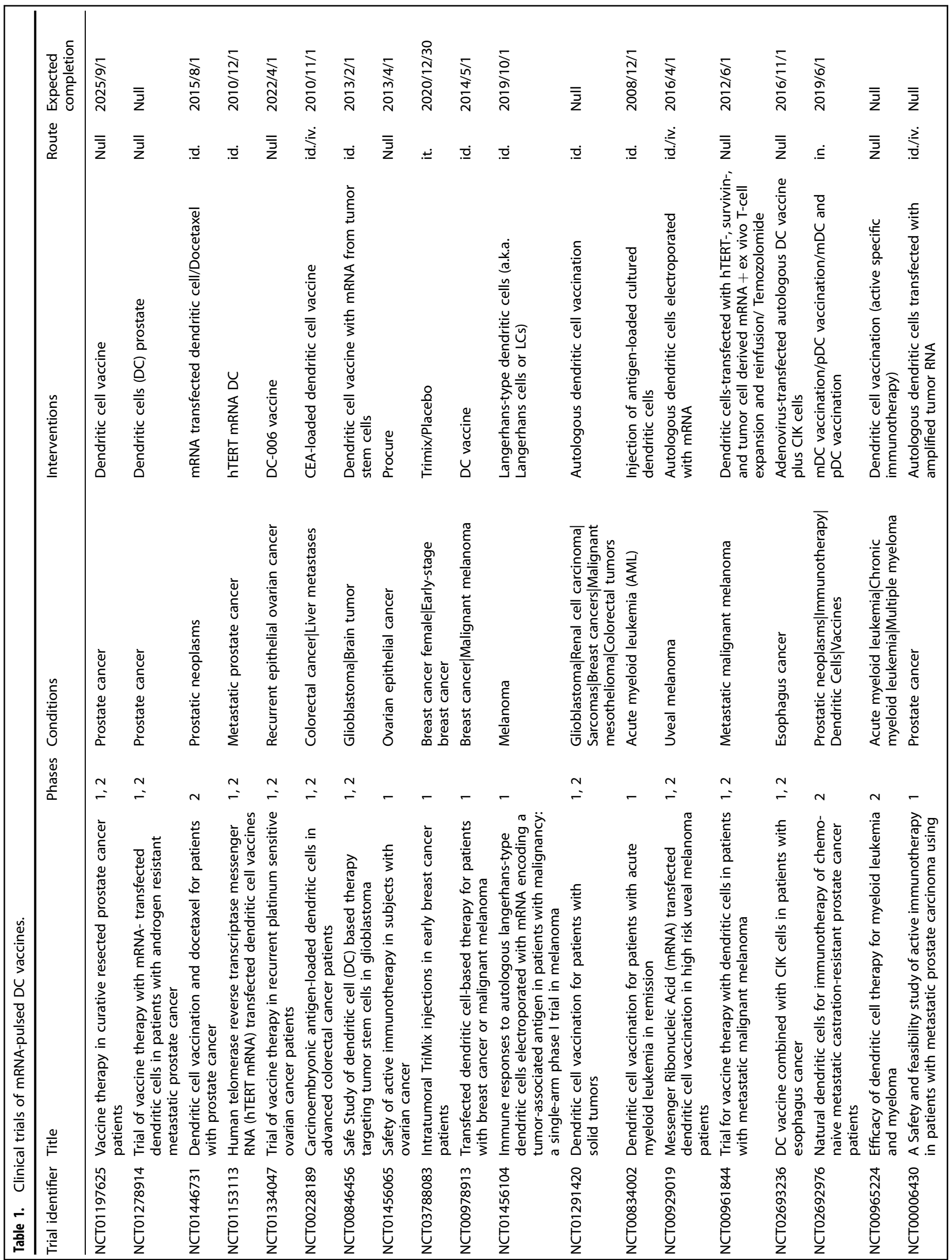




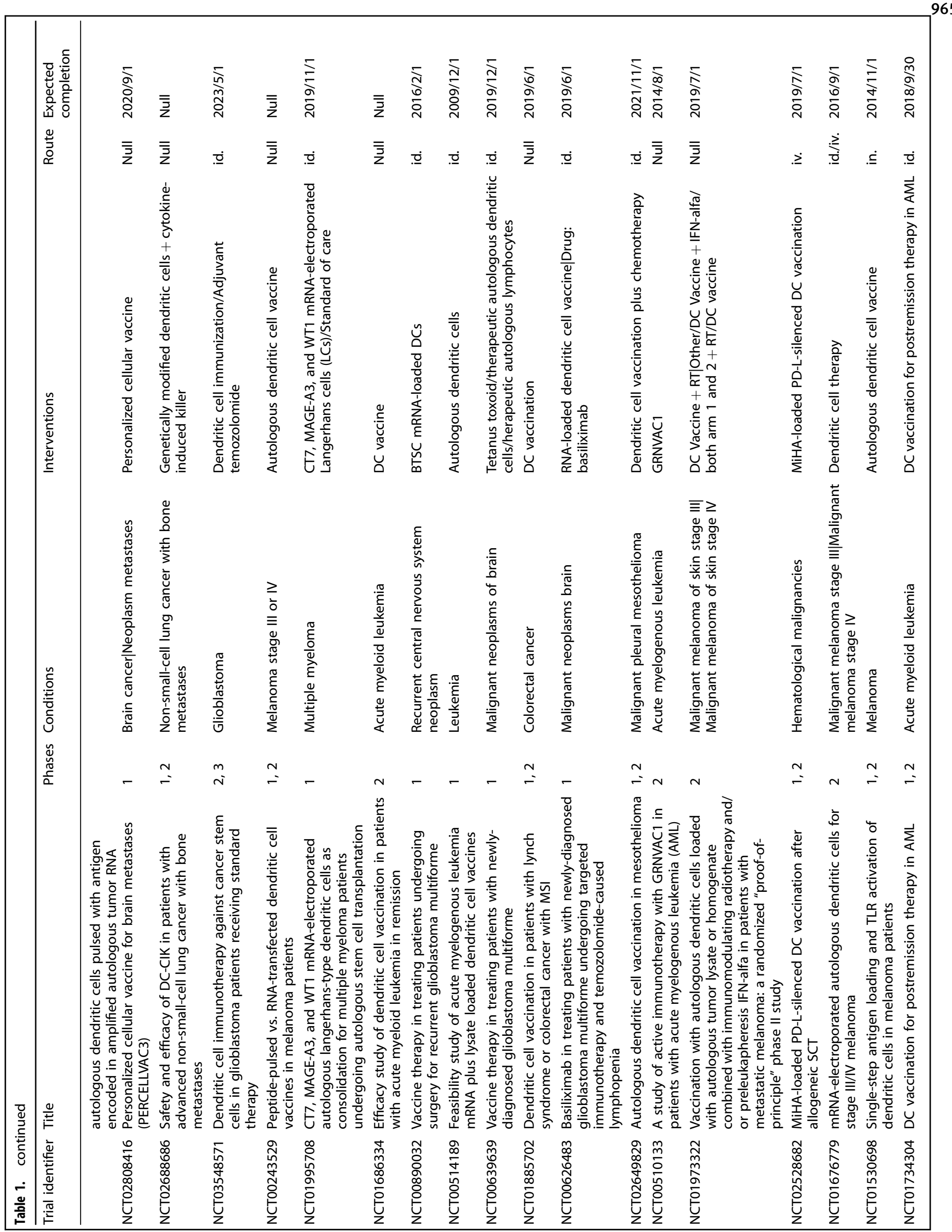




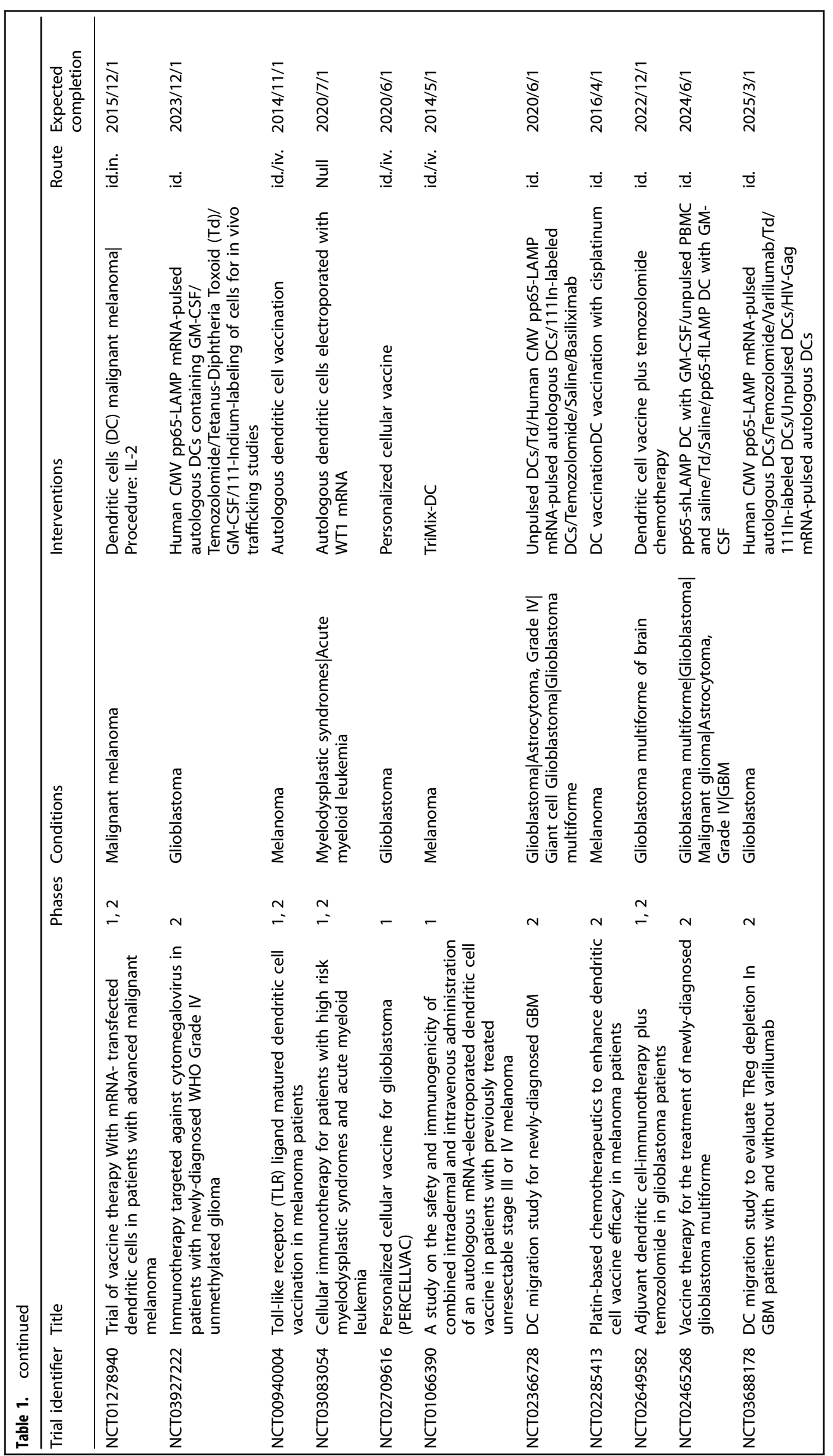


unresectable stage III/IV melanoma with TriMix-DCs and the antiCTLA-4 monoclonal antibody ipilimumab (NCT01302496) was performed, in which the 6-month disease control rate was $51 \%$, the overall response rate was $38 \%$ (eight complete responses and seven partial responses), and there were still seven complete responses and one partial tumor response after a median followup time of 36 months [67].

\section{OUTLOOK}

DCs play pivotal roles in initiating adaptive immune responses, and exploiting DCs for anticancer therapy is a promising strategy. However, it still faces challenges that call for imperative improvements.

Functional impairments were observed in endogenous DCs in peripheral blood and the tumor-draining lymph nodes of cancer patients [68], as well as DCs derived ex vivo from monocytes of cancer patients [69]. These dysfunctions were only partially reverted by tumor resection [68] or transforming growth factor $\beta$ (TGF- $\beta$ ) blockade [69], suggesting that further countermeasures must be taken to erase adverse imprints left by tumors on DCs and DC precursors. Culture of DCs ex vivo offers a unique window of time in which extensive direct interventions can be implemented in DCs to correct their functional defects.

It was estimated that as few as 85 DCs are sufficient for stimulating a T-cell immune response [70]. The recruitment of naive $T$ cells is highly efficient [71]. It might be slightly counterintuitive that DC vaccination involving the administration of a large amount of pulsed DCs has resulted in relatively limited success. DC subsets, derivation protocols, activation status, antigen loading, route of administration, vaccination schedules, mitigation of immunosuppression by cancer, etc. are all factors that determine the outcome of DC vaccination (Fig. 3).

DCs are heterogeneous cell populations that share similar characteristics while varying in origins and detailed functions. For most preclinical studies of DC vaccination, the subjects are bone marrow-derived DCs (BMDCs), and for most clinical trials, MoDCs are frequently used. These subsets, while from different species, are both believed to be counterparts of inflammatory DCs that exist in vivo rather than resident DCs [72, 73]. Inflammatory DCs act as replacements or complements of migratory $\mathrm{CDC} 1 \mathrm{~s}$ during inflammation [74] and can present antigens by themselves or transfer antigens to lymphoid tissue-resident DCs for efficient presentation. The latter process is important, as not all migratory DCs are well equipped for T-cell priming by themselves [75, 76]. Therefore, it might be worth attempting to derive DCs that resemble lymphoid-tissue resident DCs for vaccination purposes [77] and further discern which DC subset is most appealing to use in vaccinations.

In fact, the notion of the MoDC vaccine was challenged from inside by a recent study asserting that vaccines based on undifferentiated monocytes were superior to $D C$ vaccines in terms of anticancer efficacy in multiple murine tumor models. The anticancer efficacy depended on peptide transfer from monocytes to $\mathrm{CD}^{+}$splenic DCs (murine equivalents of human CD $141^{+}$DCs in terms of cross-presentation activity [78]) through connexin 43 gap junctions for presentation. However, connexin 43 gap junctions were permeable to peptides of no more than 11 amino acid residues; therefore, trafficking of only MHC class Irestricted rather than $\mathrm{MHC}$ class II-restricted peptides through such junctions was possible [79]. The extent of and the mechanisms by which $\mathrm{CD}^{+}{ }^{+}$T-cell responses are elicited by monocyte-based cellular vaccines have to be fully elucidated before this new vaccine formulation can impact cancer immunotherapy.

Current designs place elements from $a$ and/or $\beta$ globin genes in the $5^{\prime}$ and/or $3^{\prime}$ UTR of mRNAs to eventually increase protein productivity $[60,80,81]$; however, by exploring the repertoire of cellular and viral elements and with the help of computer-aided design, more powerful factors might be discovered for this purpose. In addition, many genes exert their influence on cancer immunity, and so it is expected that modulation of their expression and function by introduction of mRNAs other than those components of TriMix might trigger even more effective anticancer immune responses.

One cannot expect cancers to be easily controlled or even eradicated solely by a single approach. Combinatorial regimens have been and will always be a topic of heated investigation. As illustrated in Fig. 3, induction of stronger immune responses against cancer antigens and amelioration of the tumor microenvironment to facilitate infiltration and functioning of immune cells (activated $T$ included) act in synergy to eventually attain pronounced regression of tumor nodules and elimination of micrometastases. Recent studies of combinatorial therapy marked the latest efforts toward that ultimate goal [82-86].

The CRISPR base editing system guides deaminases to specific genomic locations and changes DNA sequences, thus abrogating the expression of specific genes without causing double-stranded breaks [87]. With this powerful genetic tool, DCs can be liberated from suppression by various negative regulators, such as the SOCS family, TGF- $\beta$ receptor, and IL-10 receptor. This can be done ex vivo by introduction of relevant ribonucleoprotein or the combination of relevant mRNA and sgRNA (single guide RNA) into DCs. Hopefully, increasingly potent DC vaccines can be generated through this modification process.

Ex vivo pulsed DC vaccines are an important platform into which new ideas and technologies have been continuously introduced. Hopes are high that, by bringing in these impetuses, DC vaccines will be properly armed to become a regular option for cancer immunotherapy.

\section{ACKNOWLEDGEMENTS}

This work was supported by the National Natural Science Foundation of China (81872821) and the National Key S\&T Special Projects (2018ZX09201018-024).

\section{ADDITIONAL INFORMATION}

Competing interests: The authors declare no competing interests.

\section{REFERENCES}

1. Steinman RM, Cohn ZA. Identification of a novel cell type in peripheral lymphoid organs of mice. I. Morphology, quantitation, tissue distribution. J Exp Med. 1973;137:1142-62.

2. Collin M, Bigley V. Human dendritic cell subsets: an update. Immunology. 2018; 154:3-20.

3. Anguille S, Smits EL, Bryant C, Van Acker HH, Goossens H, Lion E, et al. Dendritic cells as pharmacological tools for cancer immunotherapy. Pharmacol Rev. 2015:67:731-53.

4. Terhune J, Berk E, Czerniecki BJ. Dendritic cell-induced Th1 and Th17 cell differentiation for cancer therapy. Vaccines. 2013;1:527-49.

5. Leal Rojas IM, Mok WH, Pearson FE, Minoda Y, Kenna TJ, Barnard RT, et al. Human blood $\mathrm{CD}_{1 \mathrm{c}^{+}}$dendritic cells promote Th1 and Th17 effector function in memory $\mathrm{CD}^{+}$T cells. Front Immunol. 2017;8:971

6. Chow KV, Lew AM, Sutherland RM, Zhan Y. Monocyte-derived dendritic cells promote Th polarization, whereas conventional dendritic cells promote Th proliferation. J Immunol. 2016;196:624-36.

7. Thomas R, Yang X. NK-DC crosstalk in immunity to microbial infection. J Immunol Res. 2016;2016:7.

8. Unal A, Birekul A, Unal C, Karakus E, Köker Y. Dendritic cell production from allogeneic donor $\mathrm{CD} 34^{+}$stem cells and mononuclear cells; cancer vaccine. Blood. 2016;128:5723.

9. Plantinga $M$, de Haar CG, Dünnebach E. van den Beemt DAMH, Bloemenkamp KWM, Mokry M, et al. Cord-blood-stem-cell-derived conventional dendritic cells specifically originate from CD115-expressing precursors. Cancers. 2019;11:pii: E181.

10. Romani N, Gruner S, Brang D, Kämpgen E, Lenz A, Trockenbacher B, et al. Proliferating dendritic cell progenitors in human blood. J Exp Med. 1994;180:83-93. 
11. Sallusto F, Lanzavecchia A. Efficient presentation of soluble antigen by cultured human dendritic cells is maintained by granulocyte/macrophage colonystimulating factor plus interleukin 4 and downregulated by tumor necrosis factor alpha. J Exp Med. 1994;179:1109-18.

12. Romani N, Reider D, Heuer M, Ebner S, Kämpgen E, Eibl B, et al. Generation of mature dendritic cells from human blood An improved method with special regard to clinical applicability. J Immunol Methods. 1996;196:137-51.

13. Zhou LJ, Tedder TF. CD14 ${ }^{+}$blood monocytes can differentiate into functionally mature $\mathrm{CD}^{+} 3^{+}$dendritic cells. Proc Natl Acad Sci U S A. 1996;93:2588-92.

14. Van Acker HH, Anguille S, De Reu H, Berneman ZN, Smits EL, Van Tendeloo VF, et al. Interleukin-15-cultured dendritic cells enhance anti-tumor gamma delta $\mathrm{T}$ cell functions through IL-15 secretion. Front Immunol. 2018;9:658.

15. Versteven M. Abstract B137: preclinical evaluation of a Wilms' tumor protein 1targeted interleukin-15 dendritic cell vaccine: T-cell activity and batch production. Cancer Immunol Res. 2019;7:B137.

16. Mohty $M$, Mohty M, Vialle-Castellano A, Nunes JA, Isnardon D, Olive D, et al. IFNalpha skews monocyte differentiation into Toll-like receptor 7-expressing dendritic cells with potent functional activities. J Immunol. 2003;171:3385-93.

17. Brabants E, Heyns K, De Smet S, Devreker P, Ingels J, De Cabooter N, et al. An accelerated, clinical-grade protocol to generate high yields of type 1-polarizing messenger RNA-loaded dendritic cells for cancer vaccination. Cytotherapy. 2018;20:1164-81.

18. Jonuleit $H$, Kühn $U$, Müller G, Steinbrink K, Paragnik L, Schmitt $E$, et al. Pro-inflammatory cytokines and prostaglandins induce maturation of potent immunostimulatory dendritic cells under fetal calf serum-free conditions. Eur J Immunol. 1997:27:3135-42.

19. Vopenkova K, Mollova K, Buresova I, Michalek J. Complex evaluation of human monocyte-derived dendritic cells for cancer immunotherapy. J Cell Mol Med. 2012;16:2827-37.

20. Massa C, Thomas C, Wang E, Marincola F, Seliger B. Different maturation cocktails provide dendritic cells with different chemoattractive properties. J Transl Med. 2015;13:175.

21. Shinde P, Melinkeri S, Santra MK, Kale V, Limaye L. Autologous hematopoietic stem cells are a preferred source to generate dendritic cells for immunotherapy in multiple myeloma patients. Front Immunol. 2019;10:1079.

22. Bernhard H, Disis ML, Heimfeld S, Hand S, Gralow JR, Cheever MA, et al. Generation of immunostimulatory dendritic cells from human $\mathrm{CD}_{3} 4^{+}$hematopoietic progenitor cells of the bone marrow and peripheral blood. Cancer Res. 1995;55:1099-104.

23. Bontkes HJ, De Gruijl TD, Schuurhuis GJ, Scheper RJ, Meijer CJ, Hooijberg E, et al. Expansion of dendritic cell precursors from human $\mathrm{CD}_{3} 4^{+}$progenitor cells isolated from healthy donor blood; growth factor combination determines proliferation rate and functional outcome. J Leukoc Biol. 2002;72:321-9.

24. Kirkling ME, Cytlak U, Lau CM, Lewis KL, Resteu A, Khodadadi-Jamayran A, et al. Notch signaling facilitates in vitro generation of cross-presenting classical dendritic cells. Cell Rep. 2018;23:3658-72. e3656.

25. Helft J, Anjos-Afonso F, van der Veen AG, Chakravarty P, Bonnet D, Reis e Sousa C, et al. Dendritic cell lineage potential in human early hematopoietic progenitors. Cell Rep. 2017;20:529-37.

26. Rosa FF, Pires CF, Kurochkin I, Ferreira AG, Gomes AM, Palma LG, et al. Direct reprogramming of fibroblasts into antigen-presenting dendritic cells. Sci Immunol. 2018;3:pii: eaau4292.

27. Senju $S$, Haruta $M$, Matsumura $K$, Matsunaga $Y$, Fukushima $S$, Ikeda $T$, et al. Generation of dendritic cells and macrophages from human induced pluripotent stem cells aiming at cell therapy. Gene Ther. 2011;18:874-83.

28. Horton C, Davies TJ, Lahiri P, Sachamitr P, Fairchild PJ. Induced pluripotent stem cells reprogrammed from primary dendritic cells provide an abundant source of immunostimulatory dendritic cells for use in immunotherapy. Stem Cells. 2020;38:67-79.

29. Leone DA, Rees AJ, Kain R. Dendritic cells and routing cargo into exosomes. Immunol Cell Biol. 2018;96:683-93.

30. Saxena $M$, Bhardwaj $N$. Re-emergence of dendritic cell vaccines for cancer treatment. Trends Cancer. 2018;4:119-37.

31. Bol KF, Schreibelt G, Rabold K, Wculek SK, Schwarze JK, Dzionek A, et al. The clinical application of cancer immunotherapy based on naturally circulating dendritic cells. J Immunother Cancer. 2019;7:109.

32. Gross S, Erdmann M, Haendle I, Voland S, Berger T, Schultz E, et al. Twelve-year survival and immune correlates in dendritic cell-vaccinated melanoma patients. JCI Insight. 2017;2:e91438.

33. Mastelic-Gavillet B, Balint K, Boudousquie C, Gannon PO, Kandalaft LE. Personalized dendritic cell vaccines-recent breakthroughs and encouraging clinical results. Front Immunol. 2019;10:766.

34. Kukutsch NA, Roßner S, Austyn JM, Schuler G, Lutz MB. Formation and kinetics of MHC class l-ovalbumin peptide complexes on immature and mature murine dendritic cells. J Investig Dermatol. 2000;115:449-53.
35. Zhang H, Tang K, Zhang Y, Ma R, Ma J, Li Y, et al. Cell-free tumor microparticle vaccines stimulate dendritic cells via cGAS/STING signaling. Cancer Immunol Res. 2015;3:196-205

36. Gu X, Erb U, Büchler MW, Zöller M. Improved vaccine efficacy of tumor exosome compared to tumor lysate loaded dendritic cells in mice. Int J Cancer. 2015;136: E74-84.

37. Anguille S, Smits EL, Lion E, van Tendeloo VF, Berneman ZN. Clinical use of dendritic cells for cancer therapy. Lancet Oncol. 2014;15:e257-67.

38. Liau LM, Ashkan K, Tran DD, Campian JL, Trusheim JE, Cobbs CS, et al. First results on survival from a large Phase 3 clinical trial of an autologous dendritic cell vaccine in newly diagnosed glioblastoma. J Transl Med. 2018;16:142. Erratum in: J Transl Med. 2018;16:179.

39. Carreno BM, Magrini V, Becker-Hapak M, Kaabinejadian S, Hundal J, Petti AA, et al. Cancer immunotherapy. A dendritic cell vaccine increases the breadth and diversity of melanoma neoantigen-specific T cells. Science. 2015;348:803-8.

40. Mitchell DA, Batich KA, Gunn MD, Huang MN, Sanchez-Perez L, Nair SK, et al. Tetanus toxoid and CCL3 improve dendritic cell vaccines in mice and glioblastoma patients. Nature. 2015;519:366-9.

41. Banchereau J, Palucka AK, Dhodapkar M, Burkeholder S, Taquet N, Rolland A, et al. Immune and clinical responses in patients with metastatic melanoma to CD34 ${ }^{+}$progenitor-derived dendritic cell vaccine. Cancer Res. 2001;61:6451-8.

42. Schreibelt G, Bol KF, Westdorp $\mathrm{H}$, Wimmers $\mathrm{F}$, Aarntzen EH. Duiveman-de Boer $\mathrm{T}$, et al. Effective clinical responses in metastatic melanoma patients after vaccination with primary myeloid dendritic cells. Clin Cancer Res. 2016; 22:2155-66

43. Hsu JL, Bryant CE, Papadimitrious MS, Kong B, Gasiorowski RE, Orellana D, et al. A blood dendritic cell vaccine for acute myeloid leukemia expands antitumor $\mathrm{T}$ cell responses at remission. Oncoimmunology. 2018;7:e1419114.

44. Wculek SK, Cueto FJ, Mujal AM, Melero I, Krummel MF, Sancho D, et al. Dendritic cells in cancer immunology and immunotherapy. Nat Rev Immunol. 2020;20:7-24.

45. Rauch S, Lutz J, Kowalczyk A, Schlake T, Heidenreich R. RNActive(R) technology: generation and testing of stable and immunogenic mRNA vaccines. Methods Mol Biol. 2017;1499:89-107.

46. lavarone C, O'Hagan DT, Yu D, Delahaye NF, Ulmer JB. Mechanism of action of mRNA-based vaccines. Expert Rev Vaccines. 2017;16:871-81.

47. Van Lint S, Heirman C, Thielemans K, Breckpot K. mRNA: from a chemical blueprint for protein production to an off-the-shelf therapeutic. Hum Vaccine Immunother. 2013;9:265-74.

48. Schlake T, Thess A, Fotin-Mleczek M, Kallen KJ. Developing mRNA-vaccine technologies. RNA Biol. 2012;9:1319-30.

49. Asrani $\mathrm{KH}$, Farelli JD, Stahley MR, Miller RL, Cheng CJ, Subramanian RR, et al. Optimization of mRNA untranslated regions for improved expression of therapeutic mRNA. RNA Biol. 2018;15:756-62.

50. Zlotorynski E. The short tail that wags the mRNA. Nat Rev Mol Cell Biol. 2017;19:2-3.

51. Holtkamp S, Kreiter S, Selmi A, Simon P, Koslowski M, Huber C, et al. Modification of antigen-encoding RNA increases stability, translational efficacy, and T-cell stimulatory capacity of dendritic cells. Blood. 2006;108:4009-17.

52. Galaine J, Borg C, Godet Y, Adotévi O. Interest of tumor-specific CD4 T Helper 1 cells for therapeutic anticancer vaccine. Vaccines. 2015:3:490-502.

53. Bonehill A, Heirman C, Tuyaerts S, Michiels A, Breckpot K, Brasseur F, et al. Messenger RNA-electroporated dendritic cells presenting MAGE-A3 simultaneously in HLA class I and class II molecules. J Immunol. 2004;172:6649-57.

54. Aarntzen EH, Schreibelt G, Bol K, Lesterhuis WJ, Croockewit AJ, de Wilt JH, et al. Vaccination with mRNA-electroporated dendritic cells induces robust tumor antigen-specific $\mathrm{CD}^{+}{ }^{+}$and $\mathrm{CD}^{+}{ }^{+}$T cells responses in stage III and IV melanoma patients. Clin Cancer Res. 2012;18:5460-70.

55. Bonehill A, Tuyaerts S, Van Nuffel AM, Heirman C, Bos TJ, Fostier K, et al. Enhancing the T-cell stimulatory capacity of human dendritic cells by coelectroporation with CD40L, CD70 and constitutively active TLR4 encoding mRNA. Mol Ther. 2008;16:1170-80

56. Neyns B. A phase I clinical trial on the combined intravenous (IV) and intradermal (ID) administration of autologous TriMix-DC cellular therapy in patients with pretreated melanoma (TriMixIDIV). J Clin Oncol. 2011;29:2519.

57. Wilgenhof S, Van Nuffel AM, Benteyn D, Corthals J, Aerts C, Heirman C, et al. A phase IB study on intravenous synthetic mRNA electroporated dendritic cell immunotherapy in pretreated advanced melanoma patients. Ann Oncol. 2013; 24:2686-93.

58. Boczkowski D, Nair SK, Snyder D, Gilboa E. Dendritic cells pulsed with RNA are potent antigen-presenting cells in vitro and in vivo. J Exp Med. 1996; 184:465-72.

59. Diken M, Kreiter S, Selmi A, Britten CM, Huber C, Türeci Ö, et al. Selective uptake of naked vaccine RNA by dendritic cells is driven by macropinocytosis and abrogated upon DC maturation. Gene Ther. 2011:18:702-8. 
60. Kranz LM, Diken M, Haas H, Kreiter S, Loquai C, Reuter KC, et al. Systemic RNA delivery to dendritic cells exploits antiviral defence for cancer immunotherapy. Nature. 2016;534:396-401.

61. Diebold SS, Kaisho T, Hemmi H, Akira S. Reis e Sousa C. Innate antiviral responses by means of TLR7-mediated recognition of single-stranded RNA. Science. 2004; 303:1529-31.

62. Gerer KF, Hoyer S, Dorrie J, Schaft N. Electroporation of mRNA as universal technology platform to transfect a variety of primary cells with antigens and functional proteins. Methods Mol Biol. 2017;1499:165-78.

63. Van Nuffel AM, Corthals J, Neyns B, Heirman C, Thielemans K, Bonehill A, et al. Immunotherapy of cancer with dendritic cells loaded with tumor antigens and activated through mRNA electroporation. Methods Mol Biol. 2010;629:405-52.

64. Dewitte H, Van Lint S, Heirman C, Thielemans K, De Smedt SC, Breckpot K, et al The potential of antigen and TriMix sonoporation using mRNA-loaded microbubbles for ultrasound-triggered cancer immunotherapy. J Control Release. 2014;194:28-36.

65. McCullough KC, Bassi I, Milona P, Suter R, Thomann-Harwood L, Englezou P, et al. Self-replicating replicon-RNA delivery to dendritic cells by chitosannanoparticles for translation in vitro and in vivo. Mol Ther Nucleic acids. 2014;3:e173.

66. Chung DJ, Carvajal RD, Postow MA, Sharma S, Pronschinske KB, Shyer JA, et al. Langerhans-type dendritic cells electroporated with TRP-2 mRNA stimulate cellular immunity against melanoma: results of a phase I vaccine trial. Oncoimmunology. 2017;7:e1372081.

67. Wilgenhof S, Corthals J, Heirman C, van Baren N, Lucas S, Kvistborg P, et al. Phase II study of autologous monocyte-derived mRNA electroporated dendritic cells (TriMixDC-MEL) plus Ipilimumab in patients with pretreated advanced melanoma. J Clin Oncol. 2016;34:1330-8.

68. Almand B, Resser JR, Lindman B, Nadaf S, Clark Jl, Kwon ED, et al. Clinical significance of defective dendritic cell differentiation in cancer. Clin Cancer Res. 2000;6:1755-66.

69. Ramos RN, Chin LS, Dos Santos AP, Bergami-Santos PC, Laginha F, Barbuto JA, et al. Monocyte-derived dendritic cells from breast cancer patients are biased to induce $\mathrm{CD}^{+}{ }^{+} \mathrm{CD} 25^{+} \mathrm{Foxp}^{+}$regulatory T cells. J Leukoc Biol. 2012;92:673-82

70. Celli S, Day M, Müller AJ, Molina-Paris C, Lythe G, Bousso P. How many dendritic cells are required to initiate a T-cell response? Blood. 2012;120:3945-8.

71. van Heijst JW, Gerlach C, Swart E, Sie D, Nunes-Alves C, Kerkhoven RM, et al. Recruitment of antigen-specific $\mathrm{CD}^{+}{ }^{+} \mathrm{T}$ cells in response to infection is markedly efficient. Science. 2009;325:1265-9.

72. Segura E, Touzot M, Bohineust A, Cappuccio A, Chiocchia G, Hosmalin A, et al. Human inflammatory dendritic cells induce Th17 cell differentiation. Immunity. 2013;38:336-48.

73. Xu Y, Zhan Y, Lew AM, Naik SH, Kershaw MH. Differential development of murine dendritic cells by GM-CSF versus Flt3 ligand has implications for inflammation and trafficking. J Immunol. 2007;179:7577-84.
74. Hespel C, Moser M. Role of inflammatory dendritic cells in innate and adaptive immunity. Eur J Immunol. 2012;42:2535-43.

75. Allan RS, Waithman J, Bedoui S, Jones CM, Villadangos JA, Zhan Y, et al. Migratory dendritic cells transfer antigen to a lymph node-resident dendritic cell population for efficient CTL priming. Immunity. 2006;25:153-62.

76. Gurevich I, Feferman T, Milo I, Tal O, Golani O, Drexler I, et al. Active dissemination of cellular antigens by DCs facilitates $\mathrm{CD}^{+}$T-cell priming in lymph nodes. Eur J Immunol. 2017;47:1802-18.

77. Garg AD, Coulie PG, Van den Eynde BJ, Agostinis P. Integrating next-generation dendritic cell vaccines into the current cancer immunotherapy landscape. Trends Immunol. 2017;38:577-93.

78. Palucka K, Banchereau J, Mellman I. Designing vaccines based on biology of human dendritic cell subsets. Immunity. 2010;33:464-78.

79. Huang MN, Nicholson LT, Batich KA, Swartz AM, Kopin D, Wellford S, et al. Antigen-loaded monocyte administration induces potent therapeutic antitumor T cell responses. J Clin Invest. 2020;130:774-88.

80. Reinhard K, Rengstl B, Oehm P, Michel K, Billmeier A, Hayduk N, et al. An RNA vaccine drives expansion and efficacy of claudin-CAR-T cells against solid tumors. Science. 2020;367:446-53.

81. Richner JM, Himansu S, Dowd KA, Butler SL, Salazar V, Fox JM, et al. Modified mRNA vaccines protect against Zika virus infection. Cell. 2017;169:176.

82. Rodríguez-Ruiz ME, Perez-Gracia JL, Rodríguez I, Alfaro $C$, Oñate $C$, Pérez $G$, et al Combined immunotherapy encompassing intratumoral poly-ICLC, dendritic-cell vaccination and radiotherapy in advanced cancer patients. Ann Oncol. 2018 29:1312-9.

83. Nowicki TS, Berent-Maoz B, Cheung-Lau G, Huang RR, Wang X, Tsoi J, et al. A pilot trial of the combination of transgenic NY-ESO-1-reactive adoptive cellular therapy with dendritic cell vaccination with or without Ipilimumab. Clin Cancer Res. 2019;25:2096-108.

84. Vo MC, Jung SH, Chu TH, Lee HJ, Lakshmi TJ, Park HS, et al. Lenalidomide and programmed death-1 blockade synergistically enhances the effects of dendritic cell vaccination in a model of murine myeloma. Front Immunol. 2018;9:1370.

85. Hirooka $Y$, Kawashima H, Ohno E, Ishikawa T, Kamigaki T, Goto S, et al. Comprehensive immunotherapy combined with intratumoral injection of zoledronate-pulsed dendritic cells, intravenous adoptive activated T lymphocyte and gemcitabine in unresectable locally advanced pancreatic carcinoma: a phase I/II trial. Oncotarget. 2018;9:2838-47.

86. Soliman H, Khambati F, Han HS, Ismail-Khan R, Bui MM, Sullivan DM, et al. A phase-1/2 study of adenovirus-p53 transduced dendritic cell vaccine in combination with indoximod in metastatic solid tumors and invasive breast cancer. Oncotarget. 2018;9:10110-7.

87. Molla KA, Yang Y. CRISPR/Cas-mediated base editing: technical considerations and practical applications. Trends Biotechnol. 2019;37:1121-42. 